\title{
Saudação ao Professor Renato Dornelas Câmara Neto ao receber o título de Acadêmico do Ano de 2018 da Academia Pernambucana de Medicina em 2018*
}

* Esta saudaçãofoi proferida por Marcelo Moraes Valença na Academia Pernambucana de Medicina em 19 de dezembro de 2018.

Agradeço ao Professor Hildo Rocha Cisne de Azevedo Filho, presidente da Academia Pernambucana de Medicina, no qual eu saúdo todos os ilustres colegas aqui presentes, a oportunidade e a grande honra de ter sido indicado para saudar o confrade Professor Renato Dornelas Câmara Neto a quem foi auferido o título de Acadêmico do Ano de 2018 da APM.

Minhas senhoras e meus senhores,

Esta noite tem algo de muito especial. Estamos homenageando vários níveis dentro do espectro da formação de um grande médico. Desde o estudante de Medicina, passando pelo residente, até o reconhecimento do trabalho de grades mestres.

O professor Renato Câmara Neto é filho do Professor Albérico Dornelas Câmara, que no dia 17 de maio de 1972 também tomou posse na APM com um discurso enaltecendo José Bandeira Melo Filho citando que em 1914 a primeira operação cesariana no Recife foi realizada por Bandeira Filho, apesar de relato contrário registrar o também pernambucano Correia Picanço, criador da escola médica do Brasil, como o pioneiro.

Achei interessante o registro de pai e filho terem pertencido à mesma Academia de Medicina em tempos diferentes, onde apenas 118 acadêmicos tomaram posse desde sua inauguração 48 anos atrás. Algo semelhante também aconteceu com os acadêmicos da família Kelner, os professores Salomão, Miriam e Gilda.

$\mathrm{Eu}$ gostaria inicialmente de dar as boas vindas à todos aqui sentados neste auditório do Memorial da Medicina da Universidade Federal de Pernambuco, antiga Faculdade de Medicina do Recife.

Acreditem! Alguns aqui neste recinto realizaram o curso de Medicina neste prédio, curso que foi transferido para a Cidade Universitária 60 anos atrás, em 1958, data também da criação da Residência Médica na Faculdade de Medicina da UFPE pelo professor Amaury Coutinho. O professor Gentil Porto ainda sofreu o caliginoso e perverso trote no térreo deste prédio, ao ingressar no primeiro ano do curso de Medicina, em local denominado por ele como "gaiola dos feras", recinto onde estamos hoje expondo uma Galeria de Fotos Raras ainda não conhecidas por todos sobre a História da Medicina de Pernambuco. E abrimos as janelas do Museu da Medicina para mostrar uma parcela dos objetos que são testemunhas de atos de amor no tratamento de tantos pacientes por nossos grandes mestres da Medicina Pernambucana no século passado.

Por favor! Contemplem este imponente prédio, agora em reforma, às margens do nosso belo rio Capibaribe (que em Tupi significa rio das Capivaras), aqui no Derby, bem próximo à praça projetada por Burle Marx ainda nos anos 1930.

Como o nome sugere, estamos no Memorial, que no conceito é uma "instituição permanente, de interesse geral, voltada para a preservação e propagação de informações históricas compostas de dados, documentos e imagens relativas a pessoas, instituições ou lugares". No nosso caso, em particular, sobre a Medicina de Pernambuco.

Apesar do esplendor da arquitetura neocolonial do prédio, que foi criação do italiano Giacomo Palumbo, para uma pessoa que, porventura, contemple sua beleza, não é possível perceber a grandeza de tudo que aqui se iniciou e suas consequências, desde o lançamento da sua pedra fundamental em 1925. 
Vamos voltar no tempo e perceber cada detalhe na construção. Por exemplo, muito recentemente resolvemos trocar o carpete deste auditório, e vejam a surpresa de encontrarmos um piso 'tabuleiro de xadrez" que muito representa a idade do prédio. Claro! Deixamos o assoalho exposto para que aquele que o contemple se alegre com o que tem de belo. $\mathrm{O}$ terraço em torno do clautro, ai fora, possui um piso com cerâmica nas cores branca e preta de beleza singular. Encontrei esse mesmo tipo no banheiro projetado por Alberto Santos Dumont, em sua casa de verão construída em 1918 em Petrópolis, conhecida como "A Encantada", que acredito muitos aqui presentes já a conheceram.

Vocês perceberam, ao entrar no edifício, o vitral simbolizando a arte na Medicina/Farmácia, com o cálice de Hígia e serpente, coroa de louros, coruja e o ano de sua inauguração, em 1927. É uma obra de arte do italiano Cesare Formenti, coroando a escadaria que nos guiou para este andar superior onde estamos agora.

É oportuno avisar para todos que cerca de duas semanas atrás, depois de várias décadas, voltamos a ser Faculdade de Medicina, como um Centro independente, no modelo da Faculdade de Direito. Antes o curso de Medicina pertencia ao CCS.

Ainda em relação ao curso de Medicina em Pernambuco para aqueles que ainda não sabem, logo após a Revolução de 1817, foi criado o Hospital Militar no Convento do Carmo pelo violento Governador Luiz do Rego Barreto para, no mesmo ano, uma escola de cirurgia ser idealizada por José Eustáquio Gomes. Iniciativa fundamental para o ensino da Medicina, visando à formação do cirurgião, na época, condição diferente de médico.

Em 1841, a Sociedade de Medicina de Pernambuco foi criada, reunindo médicos, cirurgiões e farmacêuticos.

O início da Faculdade de Medicina do Recife ocorreu no dia 16 de julho de 1920. Cinco anos depois se formaram os seis primeiros médicos. Vocês podem ver no quadro a esquerda esses primeiros alunos formados e o corpo docente da época.
Hoje trabalham no Estado mais de 16 mil médicos, cerca de 11 mil em Recife. Escolas de Medicina se multiplicaram, muitas no Grande Recife, com interiorização do ensino para Caruaru, Petrolina, Garanhuns e Serra Talhada.

Alguns consideram elevado o número de escolas (13 no estado); não obstante ainda parece pouco, em um Estado com quase 10 milhões de habitantes, pela carência de médicos no Agreste e Sertão pernambucanos.

Octávio de Freitas certamente ficaria orgulhoso se soubesse a dimensão que alcançou a sua iniciativa de, quase cem anos atrás, criar a primeira escola de Medicina do Norte e Nordeste acima de Salvador, com os milhares de médicos formados (mais de 10 mil segundo o acadêmico Claudio Pina Moreira), pela inserção internacional de nossos pesquisadores e, sobretudo, com a nucleação de várias outras escolas de Medicina no Nordeste do Brasil, principalmente a Faculdade de Ciências Médicas de Pernambuco, criada no dia 28 de fevereiro de 1950 , no outro lado do rio, por professores livre docentes da antiga Faculdade de Medicina do Recife, onde nós estamos agora.

Eu pediria perdão ao Professor Renato Dornelas Câmara Neto por eu ter falado tanto sobre o Memorial da Medicina; é porque todas a vezes que venho aqui a minha alma é enfeitiçada pela magia destas paredes e fico encantado imaginando tudo que já aconteceu em cada uma das salas e seus corredores. Desde que você Renato tomou posse da cadeira número 30 entre as 50 da APM, ocupada previamente pelos professores Manoel Caetano de Barros e Alcides Codeceira Júnior, nos últimos dois anos a história do Memorial da Medicina tem se ampliada graças as suas intervenções como médico, amigo, professor, memorialista, estrategista, sempre preocupado com o grupo para que tudo ocorra perfeitamente. Seu trabalho é silencioso, sem alardes, mal se percebe o seu jeito eficiente de conseguir realizar suas metas. Por isso o seu nome foi merecidamente escolhido como o Acadêmico do ano.

O Professor Renato é pesquisador e professor aposentado de Cirurgia da UFPE. Atualmente é o primeiro Secretário da APM e Vice-presidente do Instituto Pernambucano de Historia da Medicina e seu Museu da Medicina. Ele também participa ativamente das atividades da Sociedade Brasileira de 
Médicos Escritores (Sobrames). O Memorial da Medicina alberga essas três Instituições por onde o professor Renato executa ativamente função primordial para que não só a APM, mas as outras entidades desempenhem plenamente suas funções.

A Academia Pernambucana de Medicina, na minha opinião, instituição maior da Medicina Pernambucana, foi criada no dia 17 de dezembro de 1970, pelo visionário e nosso grande Professor Fernando Jorge Simão dos Santos Figueira, na época Presidente da Sociedade de Medicina de Pernambuco, hoje Associação Médica de Pernambuco, visando a boa prática do exercício da medicina, um ensino médico de excelência, saúde pública adequada, valorização da ética médica e a preservação da memória médica de Pernambuco.

$\mathrm{Na}$ gestão do professor Hildo Azevedo, que além de presidente da nossa Academia é o presidente honorário da World Federation of Neurosurgical Societies, título que muito nos orgulha, a APM tem tomado uma atitude proativa na identificação de problemas potenciais e elaboração de estratégias para solucioná-los, buscando sempre uma Medicina de vanguarda para um futuro melhor para Pernambuco e estados vizinhos.

Neste ano discutimos sobre Judicialização da Medicina, Residência Médica em Pernambuco, Escolas de Medicina em Pernambuco, entre outros temas de extrema importância. Também neste ano a APM instituiu o Prêmio Prof. Amaury Coutinho de incentivo à Residência Médica, coincidentemente o ano do centenário desse dileto professor.

O prefeito do Recife Geraldo Júlio, recentemente, assinou no salão nobre da APM o documento que deu início a reforma da praça Octavio de Freitas na frente do Memorial da Medicina, que tem data de reinauguração no próximo dia 28 de dezembro.

O nome da praça é uma homenagem ao criador da Faculdade de Medicina do Recife, o professor Octavio de Freitas, pioneiro em muitos feitos, como por exemplo, ele foi o primeiro a ter um carro no estado de Pernambuco nos idos de 1904.

Neste ano, o Instituto Pernambucano da Historia da Medicina retornou suas funções, que foram interrompidas poucos anos atrás, com as figuras dos Professores Miguel Doherty e Renato Dornelas Câmara, como Presidente e Vice-presidente, respectivamente, e na semana passada tivemos a belíssima primeira palestra conferida pelo nosso grande professor Miguel Doerhty, com o tema "A
História da Medicina do Brasil nasceu em Pernambuco". Fiquei comovido quando escutei as palavras do professor Ney, o nosso mais novo Acadêmico Correspondente, quando comentava sobre dois professores da FMR que mais influenciaram sua formação como médico. Um deles, contava o professor Ney, era um professor grande em tamanho que "se agigantava" ao ficar de joelhos humildemente para examinar seus pequenos pacientes na enfermaria da Cirurgia Pediátrica. O muito querido Professor Miguel Doerhty.

Renato Dornelas Câmara Neto foi professor de Cirurgia da UFPE. Fez Residência Médica, Mestrado e Doutorado na UFPE. Foi bolsista do CNPq e fez pós-doutoramento no Departamento de Cirurgia do Addenbrooke's Hospital da Universidade de Cambridge, Inglaterra. Quando retornou da Inglaterra foi um dos grandes responsáveis pela implantação de transplante de órgãos em Pernambuco. Idealizador da Central de Transplante de Órgãos de Pernambuco, sendo membro da Comissão de Implantação e Presidente da Comissão de Ética (1993-1998). Foi um dos fundadores e cirurgião chefe da Unidade de Transplante Renal e Diálise do antigo Inamps, local do primeiro transplante de órgão em serviço público. $\mathrm{Na}$ sua carreira ocupou vários cargos diretivos: PAM-7-Inamps (hoje HG Areias), Hospital Barão de Lucena e Hospital das Clínicas. Foi chefe do Departamento de Cirurgia por três mandatos e pesquisador do Núcleo de Cirurgia Experimental da UFPE. Preceptor de residentes, orientador de Pibic, e professor dos cursos de mestrado e doutorado em Cirurgia da UFPE.

Publicou artigos em revistas nacionais e internacionais. Autor e coautor de vários livros. É associado do Colégio Brasileiro de cirurgiões (1985), Sociedade para o Desenvolvimento da Pesquisa em Cirurgia (1991), Transplantation Society (1995), e foi conselheiro e membro de diretoria do Cremepe de 1988 a 1998.

É sócio efetivo da Academia Pernambucana de Ciências desde 2008 e por seus serviços pela Medicina foi indicado para uma das maiores honrarias que um médico pode receber: a medalha de São Lucas em 2013, apóstolo considerado o patrono dos médicos desde o século 15 pela a arte de curar o corpo e a alma. E se não bastasse todos esses títulos e reconhecimento, Renato Dornelas Câmara Neto é um homem de uma retidão de caráter inigualável. 
Acrescentando que quando ingressei nesta casa de intelectuais, não imaginava o quanto eu tinha ainda de aprender. Todos os dias eu tomo conhecimento ou compreendo algo que faz diferença em minha vida, principalmente ouvindo palavras sábias dos confrades Hildo Azevedo, Luiz Barreto, Miguel Doerhty, Gentil Porto, Renato Dornelas, Gustavo Trindade Henriques, Gilda Kelner, Gilson Edmar, entre outros tantos sábios que transitam corredores e salas deste Memorial da Medicina.

Finalizo afirmando que o conhecimento, diferente do dinheiro, é inesgotável. É uma das poucas coisas que alguém pode dar sem perder nada. Pelo contrário, ensinado se aprende mais. E Renato Dornelas Câmara é um exemplo na dedicação à pesquisa, gestão e ensino na área da Cirurgia, seguindo os ensinamentos do grande cirurgião Theodor Billroth, pai da cirurgia abdominal moderna, que investindo na cirurgia experimental mudou o prognóstico dos pacientes submetidos à procedimentos cirúrgicos. Como muito bem escreveu Renato em seu belíssimo livro editado neste ano intitulado "Theodor Billroth - Vida, obra e legado". E muito ainda há de fazer! Precisamos muito de você Renato com sua experiência!

Obrigado! 